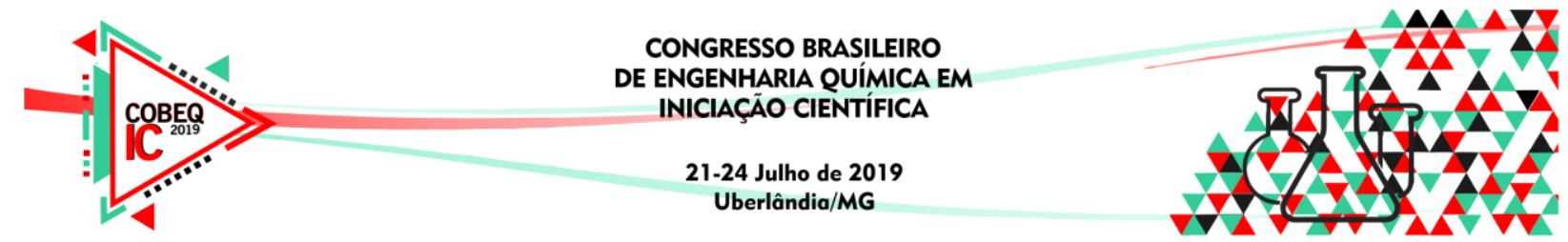

\title{
ANÁLISE DO PONTO DE CARGA ZERO (PCZ) E CURVA CINÉTICA PARA TESTE DE ADSORÇÃO DE CARVÃO ATIVADO, ORIUNDO DA SEMENTE DE MARACUJÁ, EM SOLUÇÃO DE AZUL DE METILENO
}

\author{
E. V. F. RODRIGUES ${ }^{1}$, A. E. G. de VILHENA ${ }^{1}$, D. R. PINHEIRO ${ }^{1}$ e M. C. MARTELLI ${ }^{1}$ \\ ${ }^{1}$ Universidade Federal do Pará, Faculdade de Engenharia Química \\ E-mail para contato: enzovitorfeio@gmail.com
}

\begin{abstract}
RESUMO - O presente trabalho tem por objetivo analisar o ponto de carga zero (pcz), ou do inglês zero load point (zlp), e a curva cinética referente ao carvão ativado oriundo da semente de maracujá, para o teste de adsorção no corante azul de metileno. Realizou-se um experimento de 13 pontos de $\mathrm{pH}$ para o estudo do pcz (1 a 13) e para a curva cinética analisou-se a absorbância para os tempos de 0,$5 ; 2 ; 5 ; 10 ; 20 ; 30 ; 40 ; 50$ e 60 minutos. O pcz apresentou um valor resultante de média aritmética equivalente à 5,51, propiciando a adsorção no corante azul de metileno. Este último teve o seu $\mathrm{pH}$ corrigido para 7,1 para que houvesse uma diferença significativa nos valores de $\mathrm{pH}$, permitindo uma eficiente adsorção. A curva cinética obteve uma eficiente adsorção nos primeiros 10 minutos quando comparada aos pontos de 20 e 30 minutos, os quais -apesar de apresentarem uma adsorção contínua- não foram tão eficientes como no início. Isso se deu, provavelmente, por conta do alto teor de oleosidade advindo da matéria-prima ainda in natura, a qual pode não ter sido removida completamente.
\end{abstract}

\section{INTRODUÇÃO}

O carvão ativado vem se potencializando em vários campos da sociedade, seja para fins industriais, e até mesmo medicinais, na utilização de remédios. Conforme os trabalhos de Brum (2007), o carvão ativado é um material carbonáceo e poroso preparado pela carbonização e ativação de substâncias orgânicas, principalmente de origem vegetal. São utilizados extensamente para a adsorção de poluentes em fases gasosas e líquidas, como suporte para catalisadores e na purificação de tratamento de efluentes.

De acordo com as pesquisas de Auta e Hameed (2011), para ampliar o uso do carvão ativado, busca-se cada vez mais fontes que tenham uma maior abundância e possuam um menor custo. Para isso, necessita-se construir estudos sólidos a respeito do carvão ativado em questão e sobre os testes a se realizar no mesmo. Segundo Silva (2012), o ponto de carga zero (pcz) consiste em um excelente parâmetro para análise de adsorção, pois trata do $\mathrm{pH}$ na superfície do sólido quando esse apresenta carga neutra. Portanto, com o seu conhecimento, pode-se prever se o adsorvente está mais apto a adsorver soluções catiônicas, caso o carvão esteja carregado negativamente e a solução apresente um pH maior, ou aniônico, caso aquele esteja carregado positivamente em soluções de $\mathrm{pH}$ inferior. 


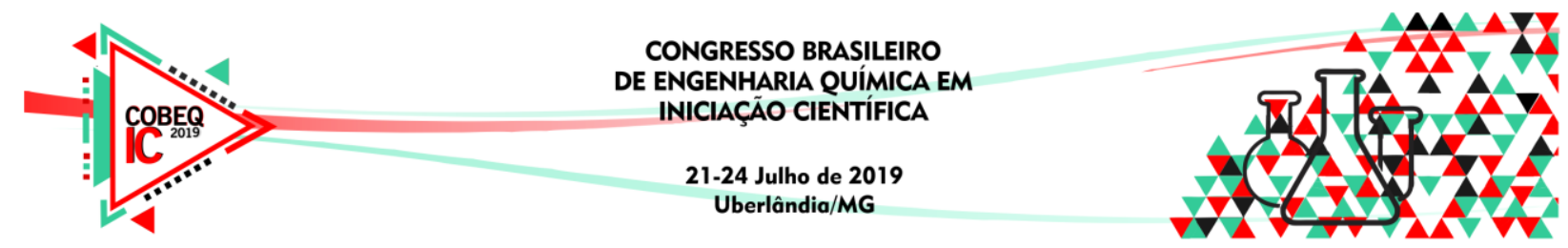

\subsection{Produção}

Segundo Claudino (2003), a fim de que se possa ter uma maior eficiência no processo de adsorção, é desejável que a matéria-prima já possua elevados teores de carbono em sua composição além de poros relativamente acentuados, do contrário a sua ativação será requisitada. Geralmente, para fins de adsorção, os dois métodos de ativação para carvão ativado são o físico e químico. Em que, segundo Fernandes (2010), o primeiro consiste na reação do carvão com gases, como, por exemplo, o dióxido de carbono $\left(\mathrm{CO}_{2}\right)$ e vapor d'água, ou seja, os gases são injetados e passam a fazer parte da estrutura do sólido. O segundo consiste na impregnação de agentes ativantes como Cloreto de Zinco $\left(\mathrm{ZnCl}_{2}\right)$, Ácido Fosfórico $\left(\mathrm{H}_{3} \mathrm{PO}_{4}\right)$, Hidróxido de Sódio $(\mathrm{NaOH})$, etc., no material, onde estes agentes proporcionarão a formação de ligações cruzadas, tornando o material menos propenso a volatilização quando aquecido a temperatura elevada.

\subsection{Trabalho acadêmico}

De acordo com Ferrari et al., (2004), as sementes de maracujá possuem alto teor de oleosidade e uma alta predominância de ácido linoleico. Isso representa um desafio na produção de carvão ativado por conta de ser necessário superfícies predominantemente secas. Portanto, o presente trabalho teve por objetivo analisar o ponto de carga zero do carvão ativado, oriundo da semente de maracujá, bem como sua curva referente à cinética de adsorção.

\section{MATERIAIS E METODOLOGIA}

Os maracujás foram adquiridos no mercado Ver-o-Peso situado na cidade de Belém, e em seguida retirou-se um total de $300 \mathrm{~g}$ de sementes. Primeiramente, as sementes passaram por um processo de limpeza, onde lavou-se a massa de total com água corrente até a completa remoção da mucilagem que as envolvia.

Após o processo de limpeza, as sementes foram secas em estufa de convecção forçada (DELEO/0814) a $40^{\circ} \mathrm{C}$ durante 72 horas. Após a secagem, elas foram moídas em moinho de martelo (MAQTRON/B611). Em função do material ainda estar preenchido por uma quantidade considerável de óleo, este teve de ser retirado por prensagem utilizando prensa hidráulica descontínua.

\subsection{Síntese e ativação do carvão}

Posteriormente à prensagem, a fim de obter-se a granulometria correta para o teste de pcz, a qual se utilizou em 65 mesh, dispôs-se de um peneirador (PRODUTEST/530), o qual peneirou a torta durante 15 minutos. Esse processo foi repetido três vezes. Trabalhando-se agora com essa faixa de granulometria, obteve-se uma massa total peneirada de aproximadamente $21 \mathrm{~g}$, a qual seguiu imediatamente para a carbonização no forno mufla (QUIMIS/Q318M) à $350^{\circ} \mathrm{C}$ durante 15 minutos. Em seguida, pesou-se uma massa de $7 \mathrm{~g}$ da amostra com o auxílio de uma balança analítica (BIOSCALE/2204) e impregnou-se as sementes carbonizadas com $1 \mathrm{ml}$ de ácido fosfórico $\left(\mathrm{H}_{3} \mathrm{PO}_{4}\right)$ à $5 \%$ (proporção 1:5) a fim de intensificar o ataque do carvão. 


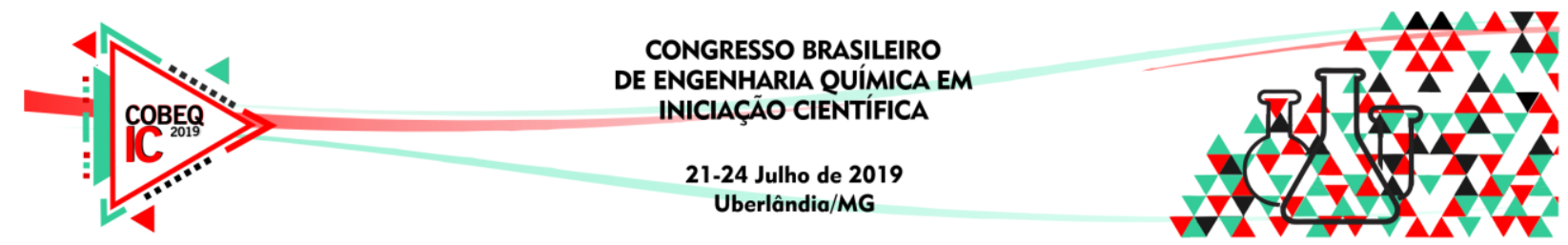

Para aumentar a eficiência do ataque, agitou-se manualmente o recipiente contendo as sementes impregnadas durante 20 minutos. Em seguida recolocou-se a amostra impregnada no forno mufla durante 30 minutos à $500^{\circ} \mathrm{C}$ para calcinação e lavou-se a massa calcinada com água destilada até atingir um $\mathrm{pH}$ neutro, com massa final de aproximadamente $5 \mathrm{~g}$.

\subsection{Caracterização do PCZ}

Com o carvão devidamente tratado, preparou-se uma solução de 1 litro de nitrato de sódio (NaNO3) em uma concentração de $0,1 \mathrm{M}$ e retirou-se um volume de $70 \mathrm{ml}$ para cada ponto na faixa de $\mathrm{pH}$ a qual se encontra de 1 até 13 . Realizou-se o ajuste de $\mathrm{pH}$ com o auxílio de ácido clorídrico $(\mathrm{HCl} ; 0,01 \mathrm{M}$ e $0,1 \mathrm{M})$ e hidróxido de sódio $(\mathrm{NaOH} ; 0,01 \mathrm{M}$ e $0,1 \mathrm{M})$. A leitura foi realizada por meio de um peagâmetro (QUIMIS/Q400RS). Ao atingir os pontos de $\mathrm{pH}$ desejados, retirou-se $60 \mathrm{ml}$ de cada para realizar o teste de pcz.

Adicionou-se uma massa de $0,5 \mathrm{~g}$ do carvão ativado para cada solução, para então serem agitados em um banho térmico (SOLAB/SL-157) à uma temperatura de $25^{\circ} \mathrm{C}$ com rotação constante durante 24 horas. Com isso, fez-se novamente a leitura do $\mathrm{pH}$ no a fim de verificar os dados para então concluir sobre o pH médio do carvão.

\subsection{Teste de adsorção}

Preparou-se uma solução mãe de azul de metileno $(500 \mathrm{mg} / \mathrm{l})$, com pH corrigido para 7,1. Este valor foi utilizado presumindo-se que o valor do pcz será de um caráter ácido, ou seja, menor, facilitando a adsorção devido à diferença de valores e, como a solução de azul de metileno é predominantemente catiônica, permitirá a adsorção das partículas positivas dessa solução quando em contato com o carvão. Diluiu-se a solução mãe para as seguintes concentrações: 20;50;80;100 e $200 \mathrm{mg} / \mathrm{l}$. Com as soluções prontas, pode-se construir a curva de calibração. Para isso, dilui-se as soluções na proporção de $1 \mathrm{ml}$ de solução para $5 \mathrm{ml}$ de água. Fez-se a leitura das soluções com o auxílio de um espectrofotômetro (SHIDMAZU, UV-1800), no comprimento padrão de onda padrão do corante, equivalente a $665 \mathrm{~nm}$.

Diluindo-se a solução mãe para uma concentração de $200 \mathrm{mg} / \mathrm{l}$ e adicionando-se uma massa de $0,3 \mathrm{~g}$ de carvão, levou-se a solução para o banho térmico à uma temperatura de $25^{\circ} \mathrm{C}$ em rotação constante, durante 1 hora. Foi realizadas coletas em tubos de ensaio para os tempos 30 segundos; $2 ; 5 ; 10 ; 20 ; 30 ; 40 ; 50$ e 60 minutos. Os tubos de ensaio foram então centrifugados em uma centrífuga de bancada (QUIMIS/Q222T116) durante 20 minutos e então filtrados por meio de um filtro acoplado à uma seringa. Utilizou-se novamente a diluição de $1 \mathrm{ml}$ de solução para $5 \mathrm{ml}$ de água destilada, e finalmente fez-se a leitura no espectrofotômetro.

\section{RESULTADOS E DISCUSSÕES}

\subsection{Curva do ponto de carga zero}

A figura 1 evidencia a curva do pcz em relação ao $\mathrm{pH}$ inicial e final do experimento, bem como os dados obtidos no processo. 


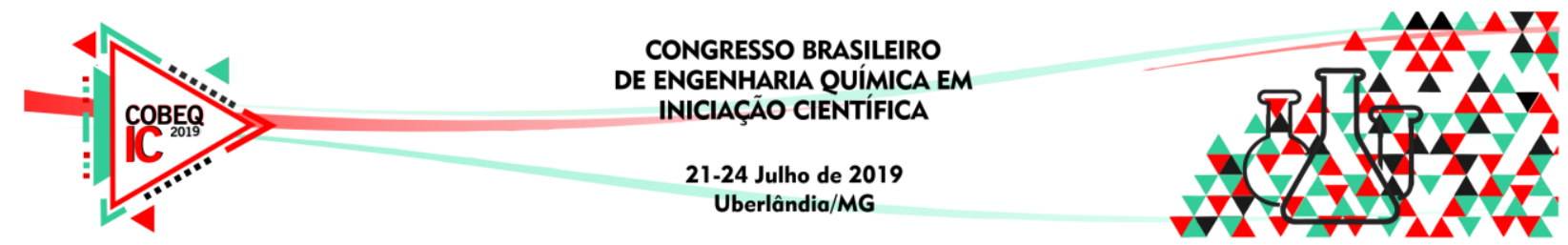

Figura 1- Curva pcz de acordo com dados de $\mathrm{pH}$
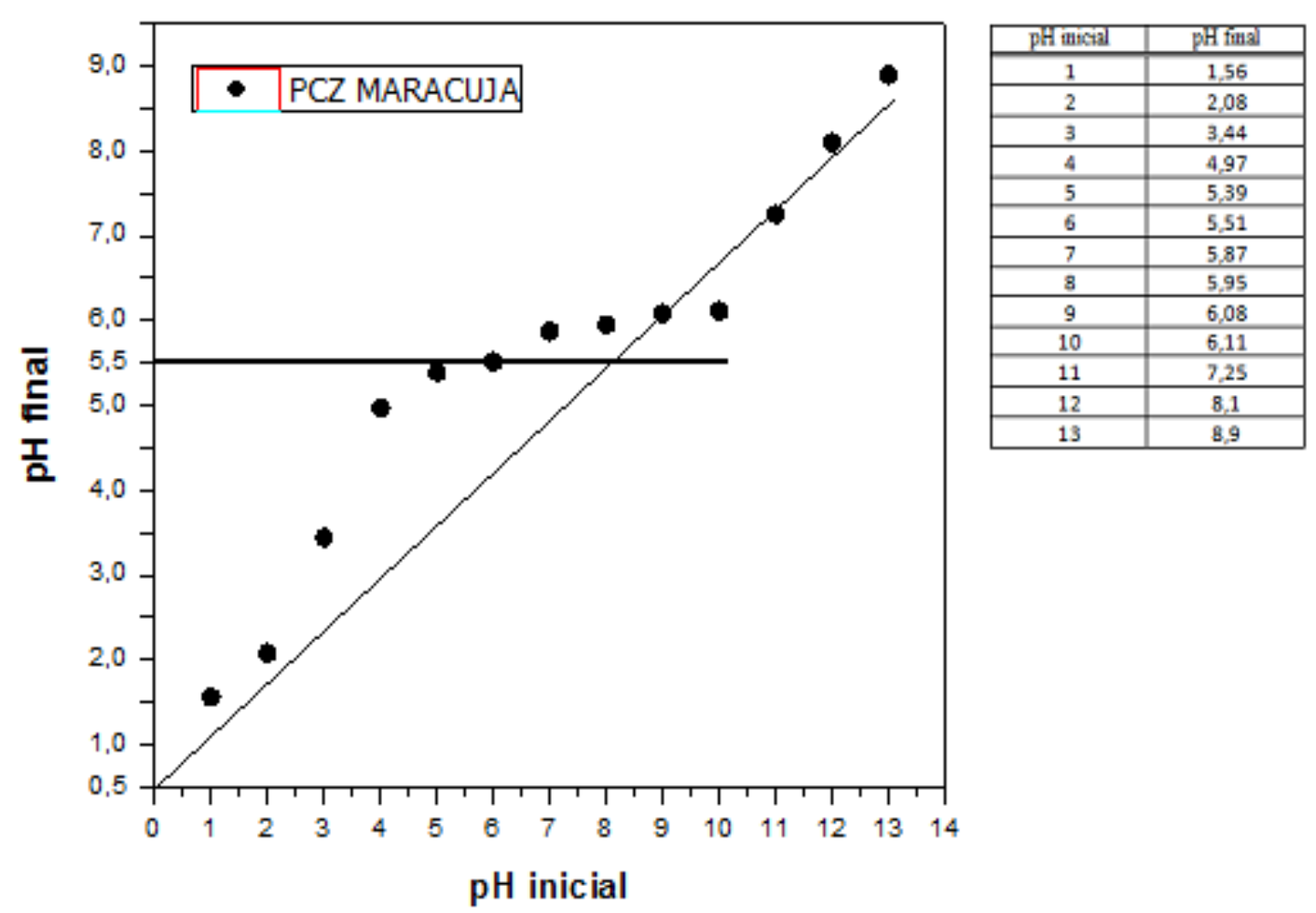

Com os dados obtidos, pode-se descobrir o ponto de carga zero por meio da média aritmética, o qual o pH final apresenta pouca variação. Com isso, conclui-se que o pcz referente à semente de maracujá é 5,51. Isso está de acordo com a teoria, visto que a solução de azul de metileno possui um pH maior e essa é uma solução predominantemente catiônica, o que favorece a adsorção.

\subsection{Curva cinética}

A fim de construir a curva de calibração, os resultados provenientes das absorbâncias lidas no espectrofotômetro foram corrigidos, devido à diluição utilizada de 1:5. A figura 3 evidencia a correção dos valores, bem como o gráfico da curva gerada da absorbância em função da concentração.

Figura 2- Gráfico referente à curva de calibração 

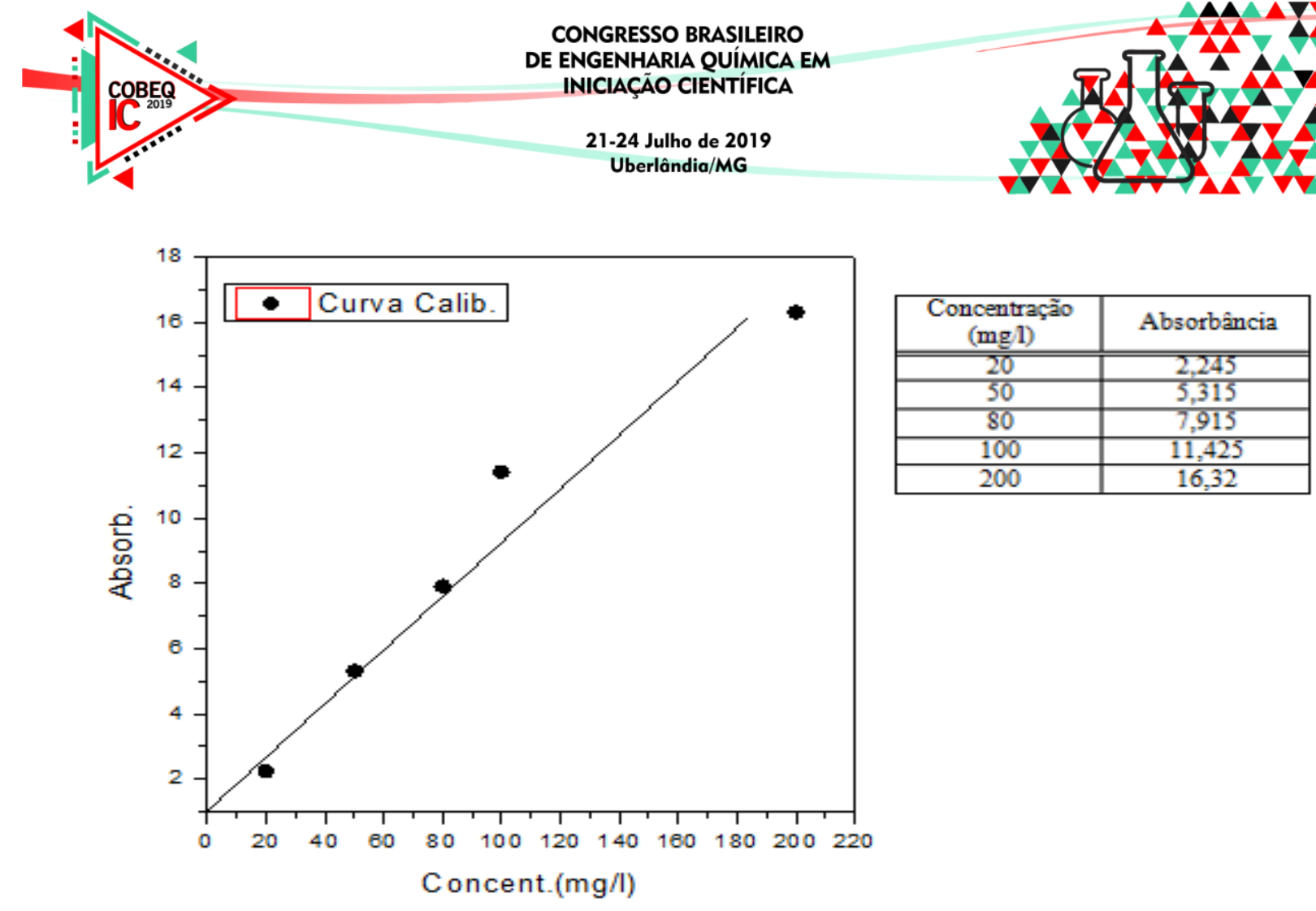

O gráfico evidencia o comportamento padrão crescente da absorbância da solução de azul de metileno. Segundo Sassaki (2017), a absorbância é diretamente proporcional à concentração de corante no meio, conforme explicita o gráfico. A fim de obter os dados da concentração na fase líquida $(\mathrm{Ca})$, utilizou-se a equação 1 , o qual consiste no produto da absorbância da amostra $(\mathrm{Ab})$ pela razão entre a concentração do padrão $(\mathrm{Cp})$ e absorbância do padrão (Ap). A figura 3 mostra a ilustra a respectiva curva cinética de absorbância em função do tempo de coleta designado.

$$
C a=A b \cdot C p / A p
$$

Figura 3 - Curva cinética para gerada nos tempos estipulados

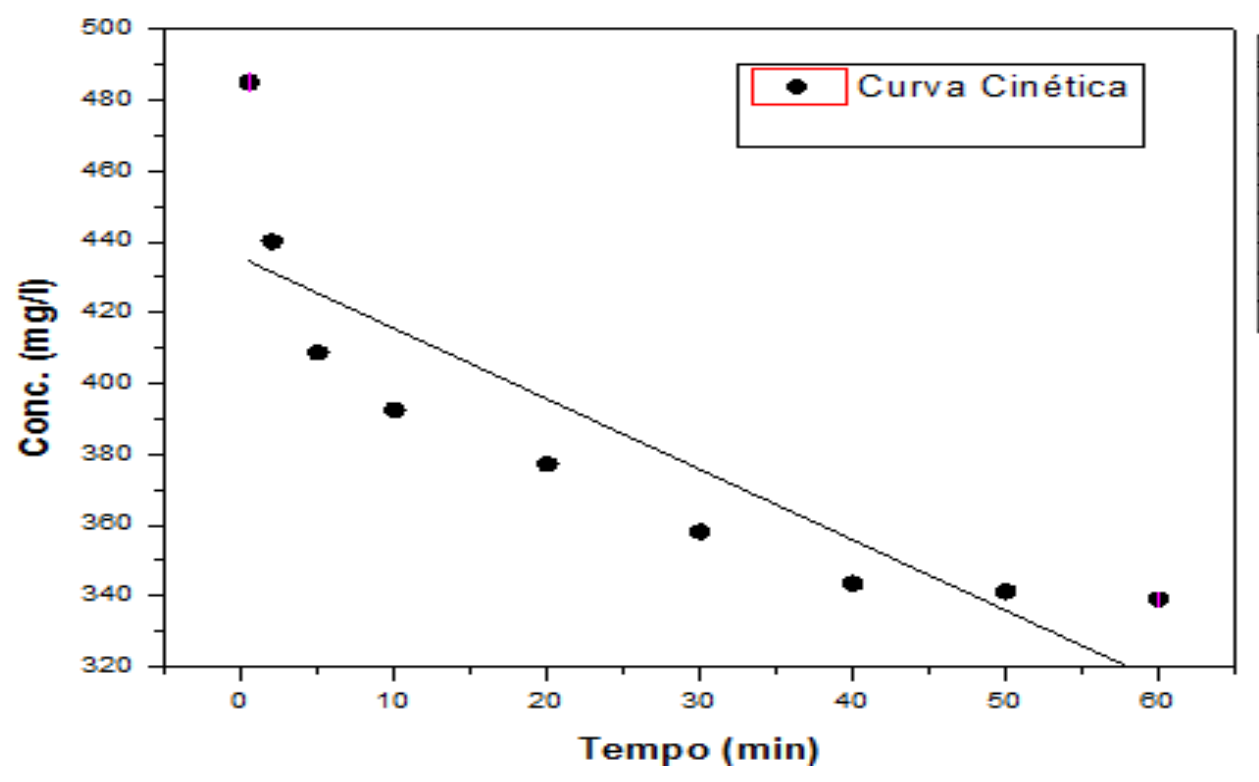

\begin{tabular}{|c|c|}
\hline Tempo (min) & $\mathrm{C}_{2}$ (mg I) \\
\hline \hline 0,5 & 485 \\
\hline 2 & 440 \\
\hline 5 & 408,7 \\
\hline 10 & 392,5 \\
\hline 20 & 377,1 \\
\hline 30 & 358,1 \\
\hline 40 & 343,4 \\
\hline 50 & 341,2 \\
\hline 60 & 339 \\
\hline
\end{tabular}




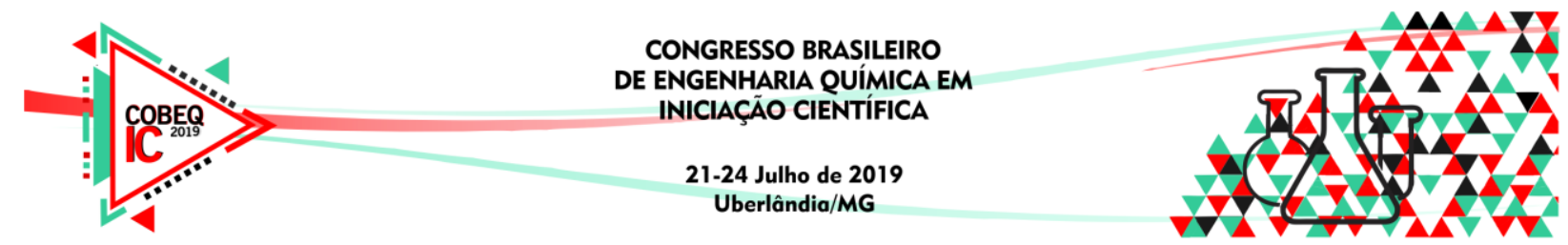

O gráfico indica que nos primeiros 10 minutos, houve uma rápida adsorção quando comparado aos pontos de 20, 30 e 40 minutos, onde foi menos intensa, porém contínua. Podese atribuir isso devido ao caráter oleoso da semente de maracujá, a qual pode conter óleo restante em pequenas quantidades que podem não ter sido removido totalmente durante o tratamento.

\section{CONCLUSÃO}

Ainda que o caráter oleoso da semente possa ter influenciado nos resultados, a curva de pcz concluiu um pH ácido e a curva cinética, por sua vez, uma adsorção contínua e mais eficiente nos primeiros pontos. A adsorção nos tempos de 20 a 40 minutos obteve baixa variação na concentração da amostra, revelando a saturação do processo. Novamente é salientada a possibilidade da presença de óleo residual que pode ter interferido no processo e mantido a saturação na faixa de $340 \mathrm{mg} / \mathrm{l}$.

\section{REFERÊNCIAS}

AUTA, M.; HAMEED, B. H. Preparation of waste tea activated carbon using potassium acetate as an activating agent for adsorption of Acid Blue 25 dye, 2011.

BRUM, S. S. Preparação e caracterização de carvão ativado produzido a partir resíduos do beneficiamento do café. UFLA-MG, Brasil, 2007.

CLAUDINO, A. Preparação de carvão ativado a partir de turfa e sua utilização na remoção de poluentes. Dissertação em Engenharia Química, 90 p, 2003.

FERNANDES, K. A. N. Uso de carvão ativado de endocarpo de coco no tratamento de água. PUC-RS. 2010.

FERRARI, R. A.; COLUSSI, F.; AYUB, R. A. Caracterização de Subprodutos da Industrialização do Maracujá- Aproveitamento das Sementes. 2004.

SASSAKI, K. T. Espectrofotometria de absorção: princípios gerais. FOA-UNESP. 2017

SILVA, M. V. R. Adsorção de cromo hexavalente por carvão ativado granulado comercial na presença de surfactante aniônico, Universidade Federal do Pará, Belém, 2012. 